\title{
The effect of microwaves on constituents and antioxidant power of essential oils of Zataria multiflora and Syzygium aromaticum
}

\author{
Zahra Mansor Esmaeili ${ }^{1}$, Saeed Mohammadi Motamed ${ }^{2}$, Mahnaz Qomi ${ }^{3}$ \\ ${ }^{1} \mathrm{MSc}$ Student of Chemistry of Essential Oil Technology, Department of Chemistry of Essential Oil Technology, Faculty \\ of Medicinal Chemistry, Tehran Medical Sciences, Islamic Azad university, Tehran, Iran \\ ${ }^{2}$ Assistant Professor, Department of Pharmacognosy, Faculty of Pharmacy and Pharmaceutical Sciences, Tehran \\ Medical Sciences, Islamic Azad University, Tehran, Iran \\ ${ }^{3}$ Assistant Professor, Department of Medicinal Chemistry, Faculty of Pharmacy and Pharmaceutical Sciences, Tehran \\ Medical Sciences, Islamic Azad University, Tehran, Iran
}

\begin{abstract}
Background: Hydrodistillation is a current method to extract plant essential oils which is time consuming. It has been proposed that use of microwaves instead of direct heat could decrease the time of distillation. In this study, the effect of microwaves on chemical profile and antioxidant activity of Zatariam multiflora and Syzygium aromaticum essential oils in comparison to current hydrodistillation method was evaluated.

Materials and methods: In this study, Zataria multiflora and Syzygium aromaticum essential oils were extracted by hydrodistillation and microwave assisted hydrodistillation method. Chemical profile of essential oils were determined by GC MASS. Their antioxidant activity in inhibition of free radicals were evaluated by DPPH method.

Results: Microwave decreased the amount of thymol and eugenol in Zataria multiflora and Syzygium aromaticum essential oils respectively. Also, the antioxidant activity of essential oils extracted by microwaves decreased in comparison to current hydrodistillation method.

Conclusion: According to the results, it is necessary to evaluate the quality of essential oils before using microwaves to extract essential oils in the food, pharmaceutical and cosmetic industries. However, in order to confirm the effect of microwave waves on plant essential oils, study on more plant samples is essential.

Keywords: Essential oil, Distillation, Microwave, Antioxidant.

Cited as: Mansor Esmaeili Z, Mohammadi Motamed S, Qomi M. The effect of microwaves on constituents and antioxidant power of essential oils of Zataria multiflora and Syzygium aromaticum. Medical Science Journal of Islamic Azad University, Tehran Medical Branch 2020; 30(2): 128-133.
\end{abstract}

Correspondence to: Saeed Mohammadi Motamed

Tel: +982122640051

E-mail: smmotamed73@yahoo.com

ORCID ID: 0000-0002-4613-4149

Received: 18 Jun 2019; Accepted: 23 Jul 2019 
مجله علوم يزشكى دانشَاه آزاد اسلامى

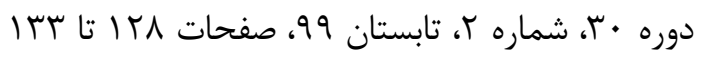

Original

Article

\section{تاثير استخراج اسانس توسط امواج مايكروويو بر روى تركيبات و قدرت آنتى

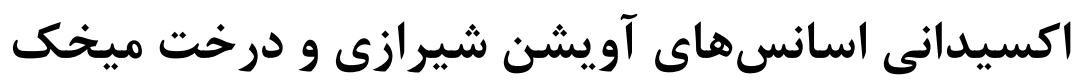

\section{زهرا منصور اسمعيلى'، سعيد محمدى معتمد'، مهناز قمى '}

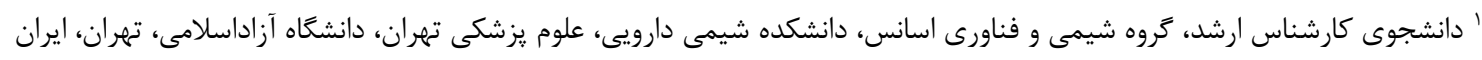

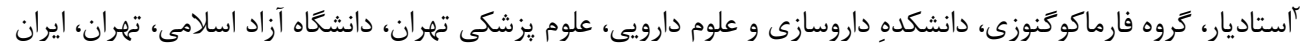

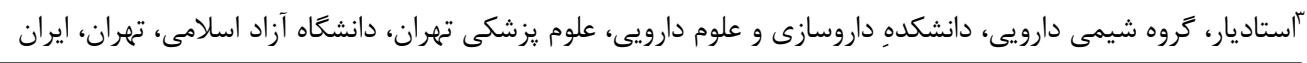
جـكيده

سابقه و هدف: يكى /ز عمدهترين روشهاى /ستخراج /سانسها روش تقطير با آب (hydrodistillation) است كه كرجه بسيار متداول

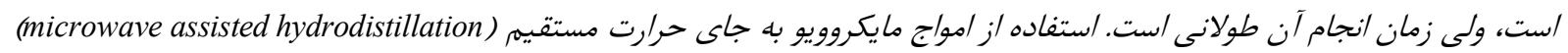

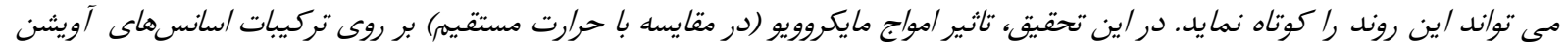

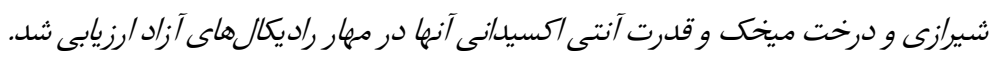

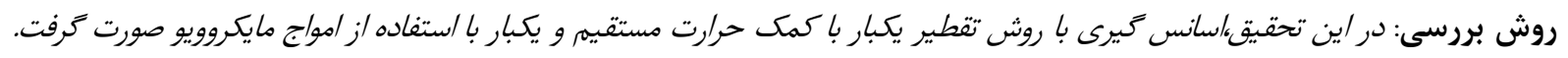

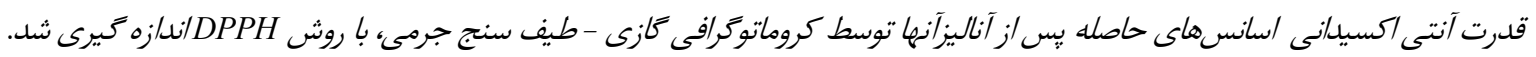

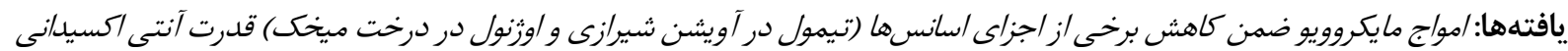

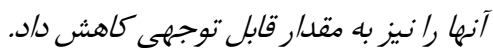

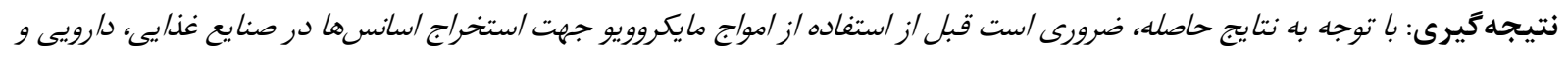

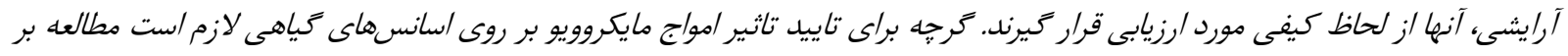

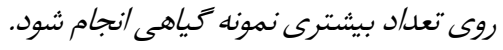

واثزان كليدى:/سانس، تقطير، مايكروويو، آنتى اكسيدان.

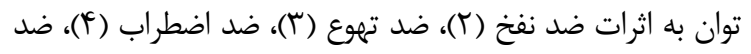

مقدمه

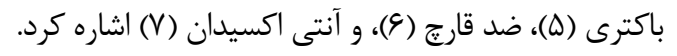

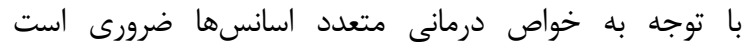

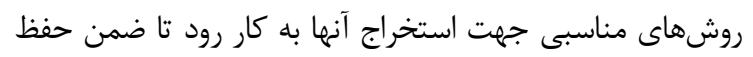
تركيبات آنها، خواص درمانى آنها نيز حفظ شود.

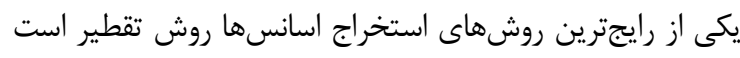

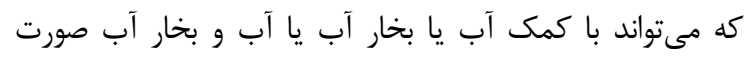

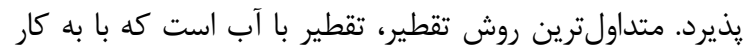

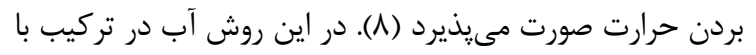

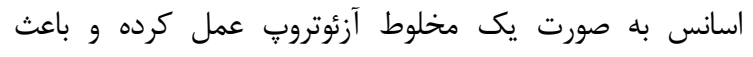

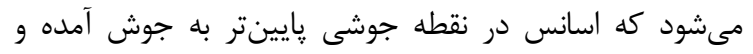
اسانسها دستهاى از متابوليتهاى فرار كياهى هستند كه از نظر

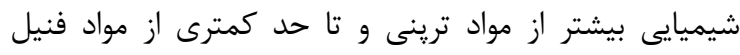

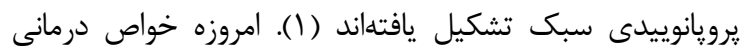

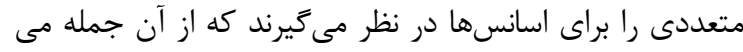

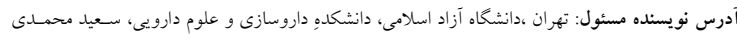

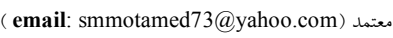
ORCID ID: 0000-0002-4613-4149 تاريخ دريافت مقاله:

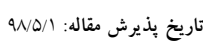




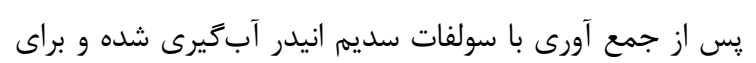

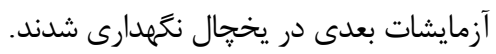

استخراج اسانس به روش تقطير با امواج مايكروويو دئري

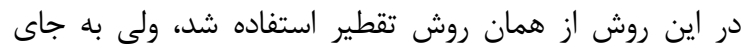

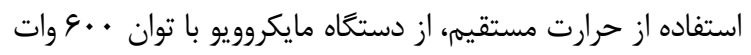
و زمان ·r دقيقه جهت استخراج اسانس استفاده شد.

\section{شناسايى اجزاى اسانسها}

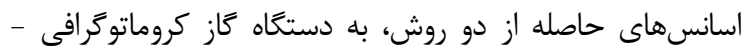

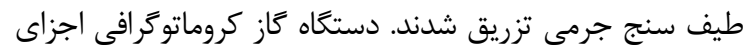

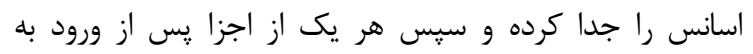
دستكاه طيف سنج جرمى شناسايى شدند (با توجه به كتر كتابخانه

$$
\text { دستخاه و نيز محاسبه انديس كواتس). }
$$

بررسى قدرت آنتى اكسيدانى اسانسها در مهيدان.

DPPH

بررسى قدرت آنتى اكسيدانى اسانسها با روش DPPH صورت

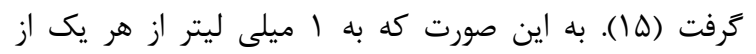

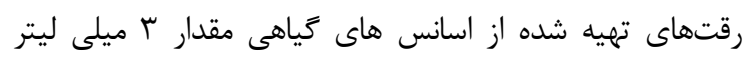

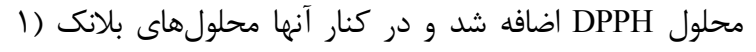

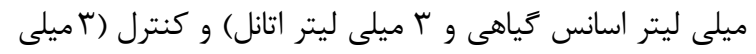

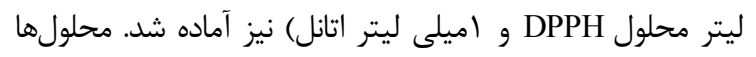

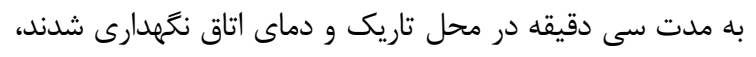
سيس جذب آنها در طول موج داله نانومتر با كمك دستخاه

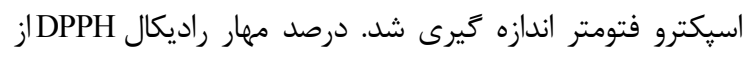

$$
\text { فرمول زير محاسبه مىشود: }
$$

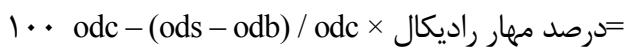

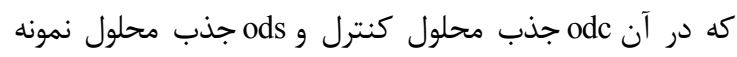

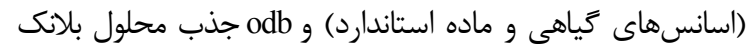

سيس از روى درصد مهارمحاسبه شده براى غلظتهاى مختلف

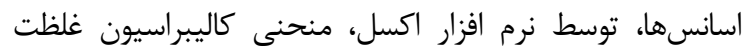

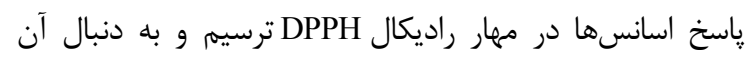
معادلات ركرسيون حاصل شد و از اين معادلات، IC50 اسانسها

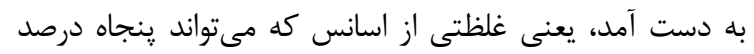
راديكال هاى DPPH را مهار كند.

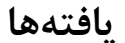

بازده اسانس كيرى براى آويشن شيرازى با ك روش حرارت

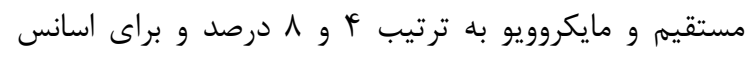
ميخك به ترتيب r ا و ها د درصد محاسبه شد.
بتواند به صورت بخار از زياه همراه بخار آب جدا شود، سيس

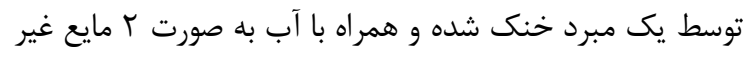

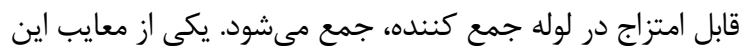

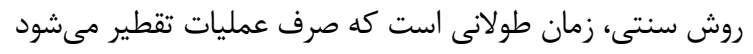

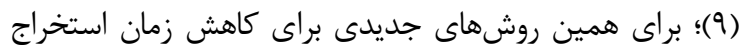

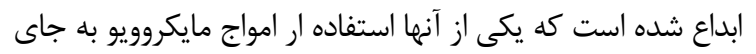

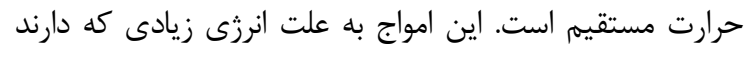

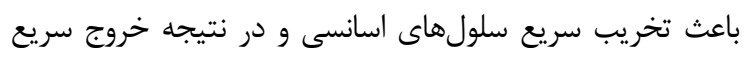

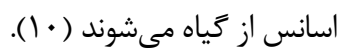

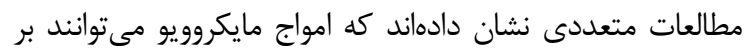

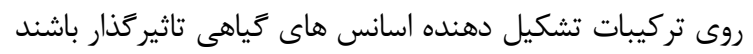

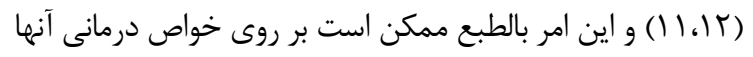
اثر بحذارد. آنتى اكسيدانها تركيباتى هستند كه با مكانيسمهاى مختلفى

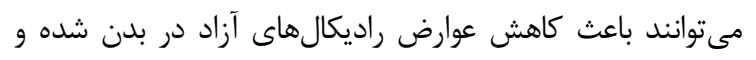

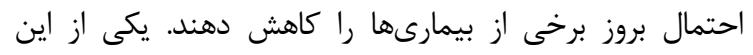

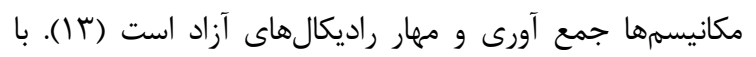

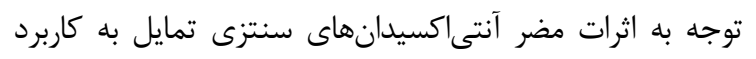

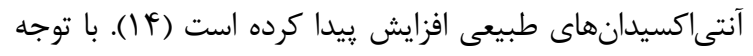

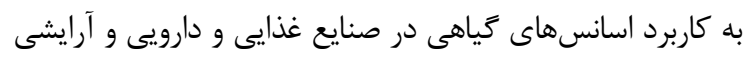

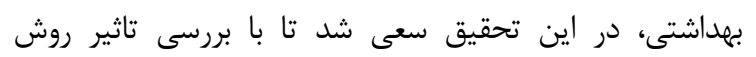

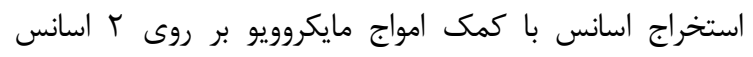

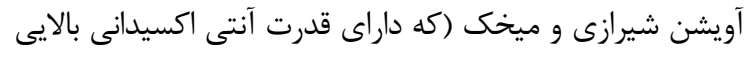

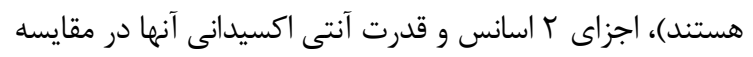

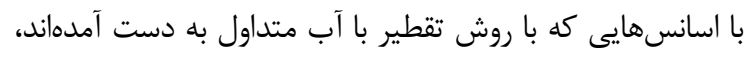

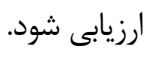

\section{مواد و روشها تهييه Fياهان}

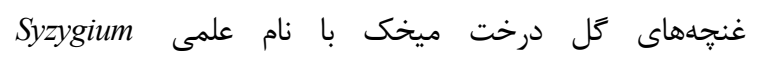
aromaticum (L.) Merr. \& L.M. Perry آويشن شيرازى با نام علمى Zataria multiflora Boiss. عطارى وزير نظام در بازار تهران خريدارى و يس إمى از شناسايى

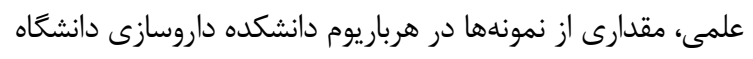

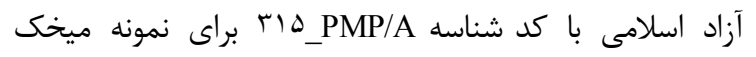
و 241_PMP/A براى نمونه آويشن شيرازى نكمهدارى شد. استخراج اسانس به روش تقطير با آب ندي

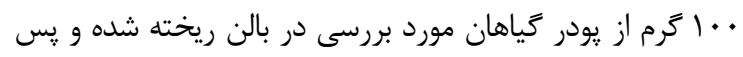

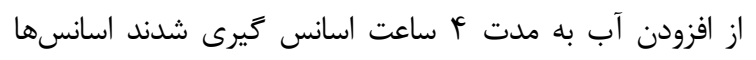


جدول ب نمايش داده شده است. لازم به ذكر است كه هر קه اين عدد كمتر باشد، نشان دهنده قدرت بالاى نمونه در مهار راديكال هاى آزاد است.

\section{بحث}

آنتى اكسيدانها با مكانيسمهاى متفاوتى ازجمله مهار راديكال آزاد مىتوانند از بروز برخى از بيمارىها يِيشگيرى كنند (1) (1).

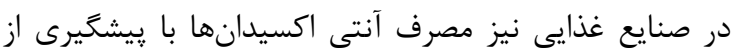
اكسيداسيون باعث افزايش پايدارى و ماندكارى غذاها مىشود (IV) تمايل به آنتى اكسيدانهاى طبيعى افزايش يافته است (If).

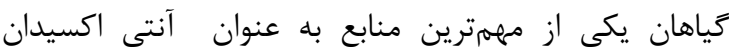
طبيعى در نظر گرفته مى شيوند.

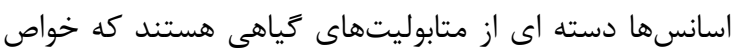

شناسايى اجزاى كياهان

با محاسبه انديس كواتس و مقايسه آنها با انديس كواتس

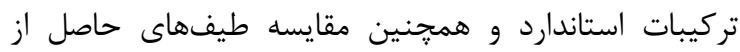
طيف سنج جرمى با طيفهاى جرمى تركيبات استاندارد، شناسايى تركيبات موجود در اسانسهاى آويشن شيرازى و

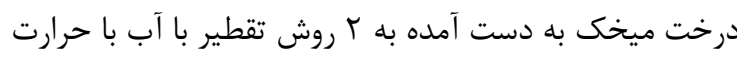

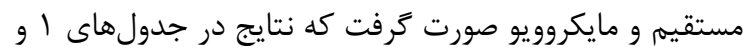
r نمايش داده شده است. r تركيب عمده اسانس ميخك در هر r روش استخراجى اوزنول و ترانس كاريوفيلن بودند و براى

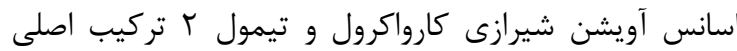
بودند.

تعيين قدرت آنتى اكسيدان اسانسها در مهار راديكال

DPPH

IC50

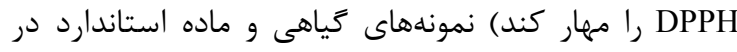

\begin{tabular}{|c|c|c|c|}
\hline مقدار تركيبات (.) (r) مق & مقدار تركيبات (.) (1) & انديس كواتس & تركيبات \\
\hline$r / 9 F$ & $1 / 9 V$ & 1.49 & O-cymel \\
\hline $1 / 81$ & $T / T r$ & 1.9. & Gamma terpinene \\
\hline $11 / V F$ & $V / 9 \Lambda$ & irq. & Thymol \\
\hline$V F / 91$ & $V T / \Delta F$ & 1799 & Carvacrol \\
\hline$\cdot / 49$ & $\cdot / 1 \mathrm{~V}$ & Irat & thymol acetate \\
\hline$r / \cdot \varphi$ & $T / T V$ & IrV & carvacryl acetate \\
\hline$|/| q \mid$ & $r / F F$ & $|f| \Lambda$ & trans carryo phyllene \\
\hline .199 & $1 / 1 r$ & loגr & caryophllen oxide \\
\hline
\end{tabular}

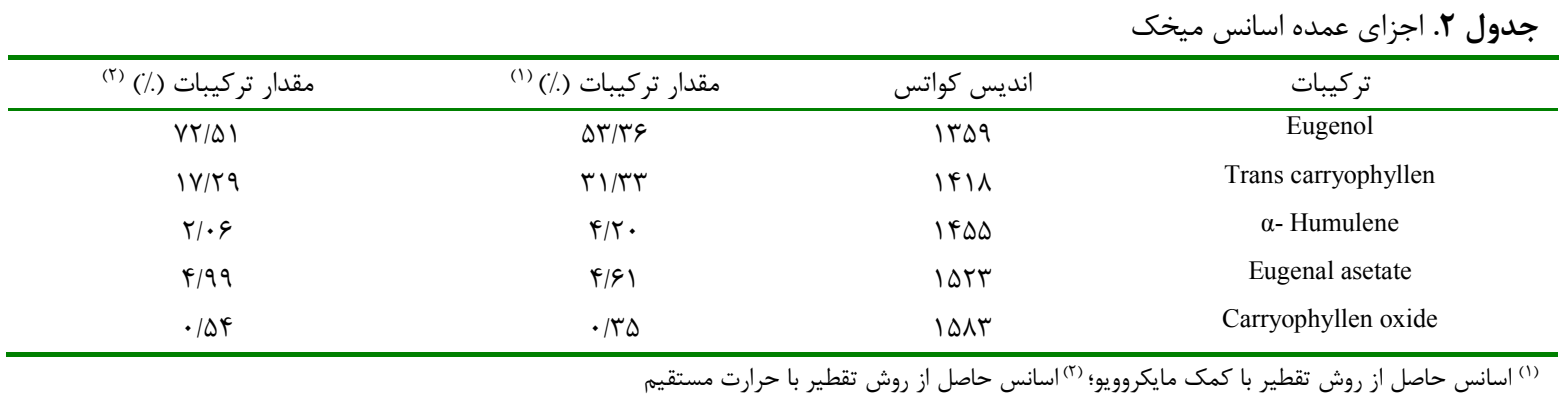

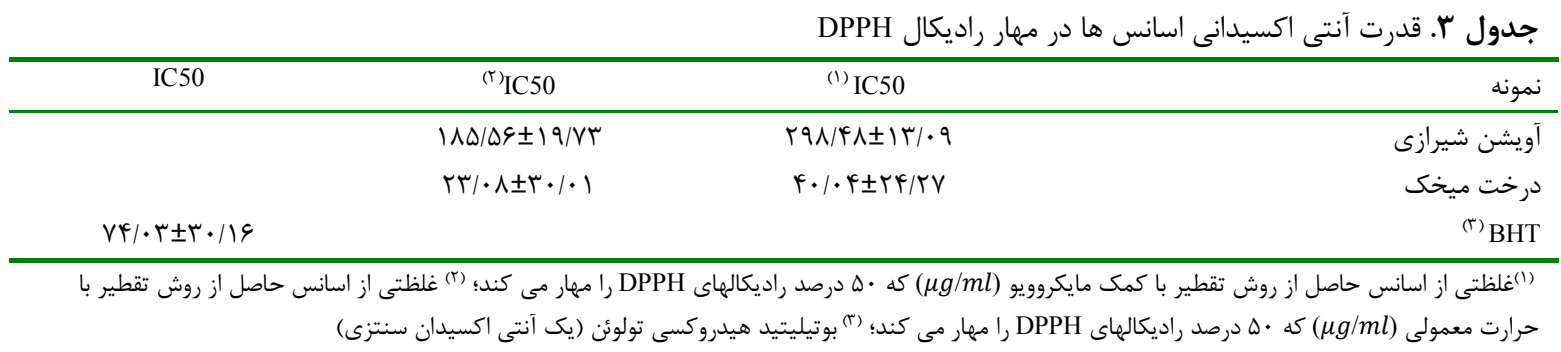


اكسيدانى اسانس درخت ميخك اوزنول و اسانس آويشن

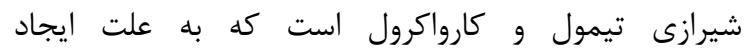

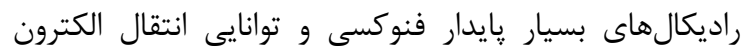

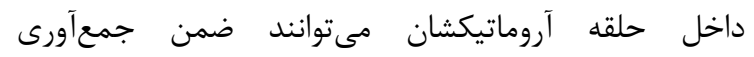
راديكالهاى آزاد از اكسيداسيون تركيبات ديكر جلوكيني

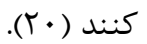
همان طور كه از جدول T مشخص است اسانس ميخك حاصل

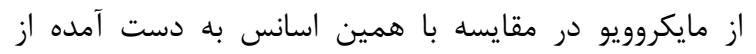

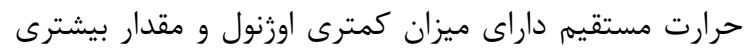
ترانس كاريوفيلن است كه با توجه به ساختار غيرآروماتيك داريك

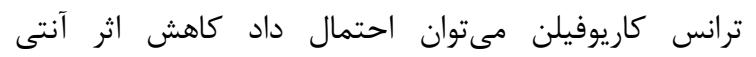

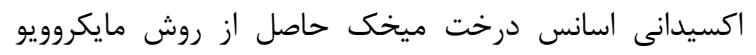
احتمالا مربوط به كاهش اوزنول موجود در اسانس باشد.

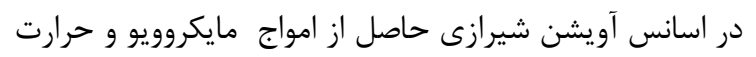

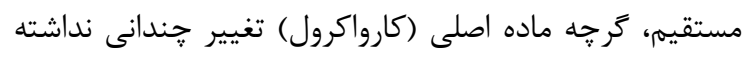

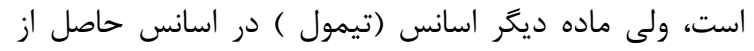

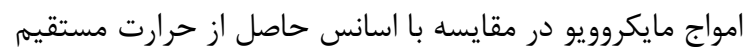

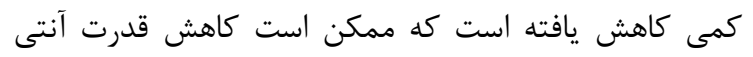

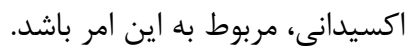

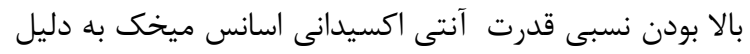

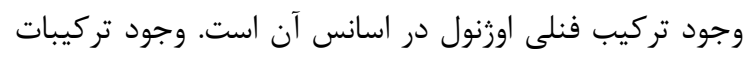

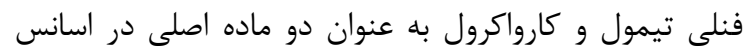
آويش شيرازى نيز مسئول اثر آنتى اكسيدانى اسانس كئى دياه

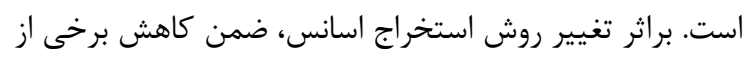

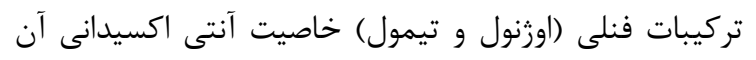
اسانسها نيز كاهش يافت؛ بنابراين كرجه استخراج اسانسها

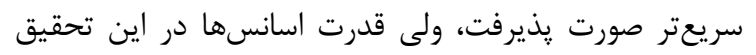
در مهار راديكال هاى آزاد كاهش يافت

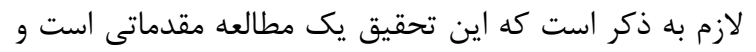

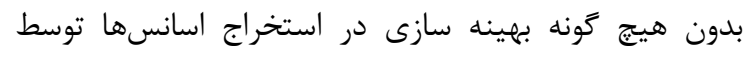

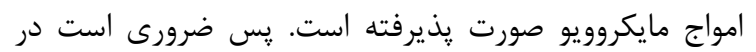

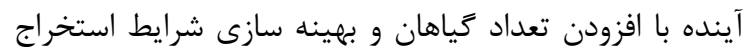

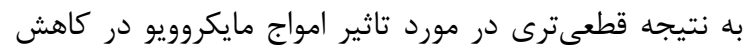
قدرت آنتى اكسيدانى نمونه هاى كياهى دست يافت دردي

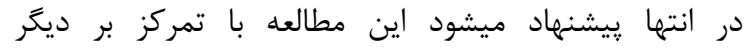
تستهاى بيولوزى (ضد باكترى، ضد قارج و....) نيز انجام كيرد

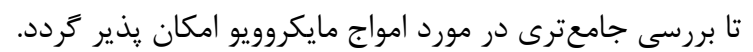

\section{REFERENCES}

1. Burcul F, Blazevic I, Radan M. Politeo O. Terpenes, phenylpropanoids, sulfur and other essential oil constituents as inhibitors of cholinesterases. Curr Med Chem 2018; 25: 1-46.
درمانى متعددى از جمله اثر آنتى اكسيدانى دارند (V). راههاى

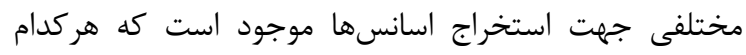

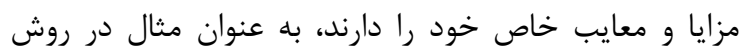

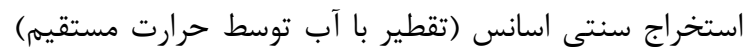

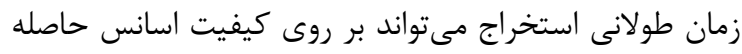

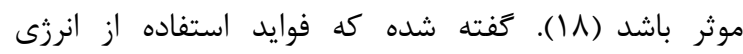

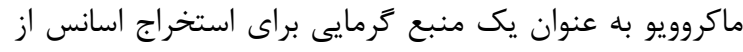

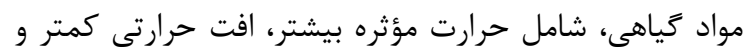
زمان لازم كمتر براى اسانس كيرى است (• (1).

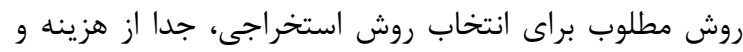

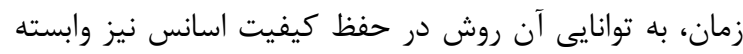

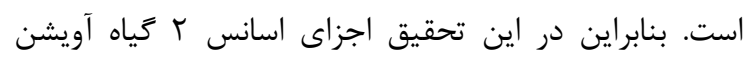

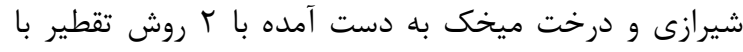

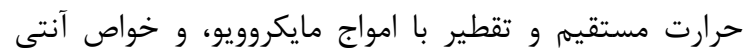

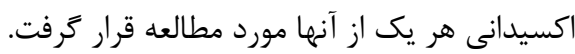
همان طور كه در قسمت نتايج بيان شد، بازده استخراج

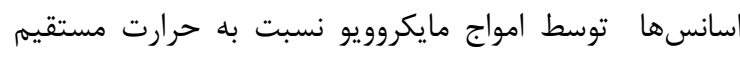

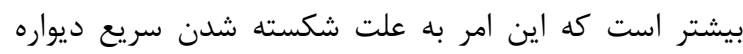

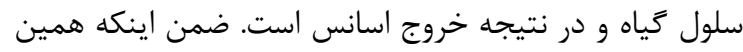

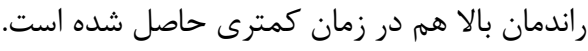

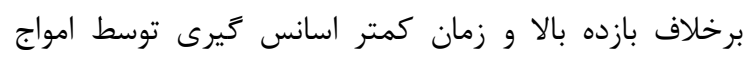
مايكروويو، با مقايسه IC50 اسانسهاى به دست آمده توسط تبال

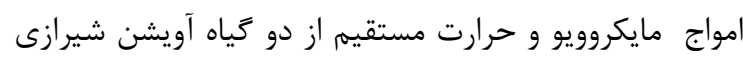

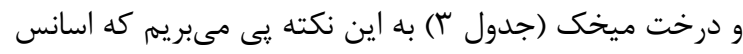

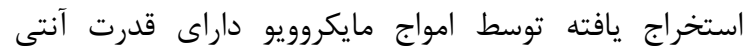

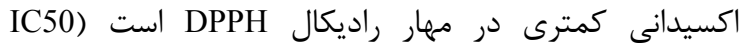

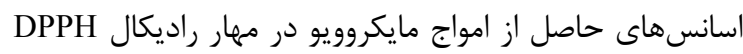

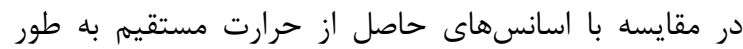

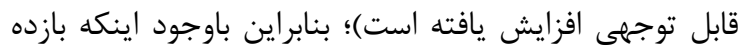

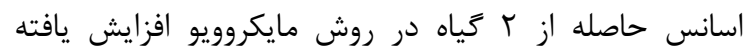

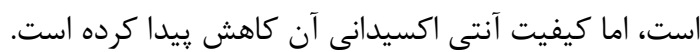

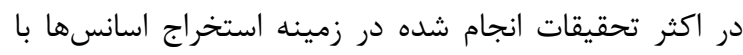

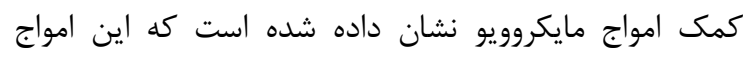
مىتوانند بر روى محتواى شيميايى اسانسها تاثير بحذارند

(1).11.19)

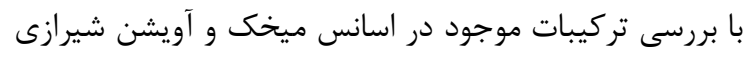

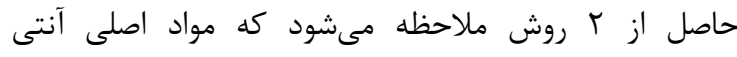


2. Larijani B, Esfahani MM, Moghimi M, Shams Ardakani MR, Keshavarz M, Kordafshari G, et al. Prevention and treatment of flatulence from a traditional Persian medicine perspective. Iran Red Crescent Med J 2016; 18 : e23664.

3. Lete I, Allué J. The effectiveness of ginger in the prevention of nausea and vomiting during pregnancy and chemotherapy. Integr Med Insights 2016; 11: 11-17.

4. Malcolm BJ, Tallian K. Essential oil of lavender in anxiety disorders: Ready for prime time? Mental Health Clinician 2017; 7: 147-155.

5. Sartoratto A, Machado ALM, Delarmelina C, Figueira GM, Marta Cristina T, Duarte MCT, et al. Composition and antimicrobial activity of essential oils from aromatic plants used in Brazil. Brazil J Microbiol 2004; 35:275-280.

6. Serra E, Hidalgo-Bastida LA, Verran J, Williams D, Malic S. Antifungal activity of commercial essential oils and biocides against Candida albicans. Pathogens 2018; 7: 15-20.

7. Emami SM, Abedindo BB, Hassanzadeh-Khayyat M. Antioxidant activity of the essential oils of different parts of Juniperus excelsa M. Bieb. subsp .excelsa and J. excelsa M. Bieb. subsp. polycarpos) K. Koch) Takhtajan (Cupressaceae). Iran J Pharm Res 2011; 10: 799-810.

8. Boutekedjiret C, Bentahar F, Belabbes R, Bessiere JM. Extraction of rosemary essential oil by steam distillation and hydrodistillation. Flavour Fragr J 2003; 18: 481-484.

9. Hesham HA, Rassem Abdurahman H Nour, Rosli M Yunus. Techniques for extraction of essential oils from plants: A review. AJBAS 2016; 10: 117-127.

10. Hong-Wu W, Yan-Qing L, Shou-Lian W, Zi-Jun Y. Kuan L. Comparison of microwave-assisted and conventional hydrodistillation in the extraction of essential oils from mango (Mangifera indica L.) Flowers. Molecules 2010; 15: 7715-7723.

11. Moradi S, Fazlali A, Hamedi H. Microwave-assisted hydro-distillation of essential oil from rosemary: comparison with traditional distillation. Avicenna J Med Biotechnol 2018; 10: 22-28.

12. Kahriman N, Yaylı B, Yücel M, Karaoglu SA, Yaylı N. Chemical constituents and antimicrobial activity of the essential oil from Vicia dadianorum extracted by hydro and microwave distillations. Records of Natural Products 2012; 6: 49-56.

13. Lobo V, Patil A, Phatak A, Chandra N. Free radicals, antioxidants and functional foods: Impact on human health. Pharm Rev 2010; 4: 118-126.

14. Taghvaei M, Jafari SM. Application and stability of natural antioxidants in edible oils in order to substitute synthetic additives. J Food Sci Technol 2015; 52: 1272-1282.

15. Blois MS. Antioxidant determinations by the use of a stable free radical. Nature 1958; 181: 1199-1200.

16. Huang D. Dietary antioxidants and health promotion. Antioxidants (Basel) 2018; 7: 9-14.

17. Wilson DW, Nash P, Buttar HS, Griffiths K, Singh R, De Meester F, et al. The role of food antioxidants, benefits of functional foods, and influence of feeding habits on the health of the older person: An overview. Antioxidants (Basel) 2017; 6: 81 .

18. Berka-Zougali B, Ferhat MA, Hassani A, Chemat F, Allaf KS. Comparative study of essential oils extracted from Algerian Myrtus communis L. leaves using microwaves and hydrodistillation. Int J Mol Sci 2012; 13: 4673-95.

19. Fadel O, Ghazi Z, Mouni L, Benchat N, Ramdani M, Amhamdi H, et al. Comparison of microwave-assisted hydrodistillation and traditional hydrodistillation methods for the Rosmarinus eriocalyx essential oils from eastern Morocco. JMES 2011; 2: 112-17.

20. Ali HM, Abo-Shady A, Sharaf Eldeen HA, Soror HA, Shousha WG, Abdel-Barry OA, et al. Structural features, kinetics and SAR study of radical scavenging and antioxidant activities of phenolic and anilinic compounds. Chem Centr J 2013; 7: 53-57. 